\title{
Salud mental de base: la teoría y la práctica centroamericana
}

Centroamérica es un territorio cataclísmico. Los desastres naturales y las conmociones sociales ya gravitan en torno al eje de la identidad de sus habitantes, aunque tanto unos como otros representan, en realidad, transgresiones episódicas a umbrales de condiciones permanentes, más que apariciones ad integrum de nuevos fenómenos.

Vivir en una situación donde la vida puede estar dependiendo, a cada momento, del interés espontáneo o, mejor dicho, de la necesidad que como ser humano despierto en los demás, nos ubica en un contexto de alta densidad psicosocial. Esto significa, en el campo de la salud mental, que si alguien tiene un problema con cualquiera, el odio generado no puede quedarse así, porque simplemente enfermaría a los integrantes de ese sistema social, empezando por los colocados en las posiciones más vulnerables y por los más débiles psicológicamente. De ahí que las masacres que se extienden hasta los retoños de las familias o a grupos enteros son, al igual que en el ámbito mafioso, una tradición. Ancestralmente, la mayoría de los centroamericanos siente que el odio de los demás, y especialmente el odio justo, enferma y hasta mata.

Esta densidad psicosocial tiene en Centroamérica un importante sustrato histórico antropológico. En general, cada comunidad maya contaba con espíritus protectores (los Balams, dirigidos hacia los cuatro rumbos del espacio vivencial colectivo), que velaban contra los enemigos comunitarios mientras la comunidad dormía. Cuando una persona de la comunidad consultaba a su shaman por padecimientos que no tenían un agente visible, aquél interrogaba sobre las enemistades más recientes, hasta dar con el "daño al chulel", el "robo del espíritu", o la supuesta magia de un cohabitante enemigo causal de esas manifestaciones. Los sacerdotes mayas, aun en la actualidad, prescriben rituales que significan una verdadera reingeniería de las relaciones cotidianas intrafamiliares e intergrupales. 
El "tiangue" o mercado precolombino era una "internet" con multiplicidad de historias y personalidades reales, donde se ejercía exquisitamente el arte del regateo y de la conversación ligera. En cada puesto familiar de venta se encontraban, más allá de los productos de la tierra y de las manos, vórtices psicosociales donde "resetear" la subjetividad personal.

La vitalidad afectiva de las redes sociales en Centroamérica, esa especie de "nebulosa energética" que enciende las partes humanas de toda ciudad, ha demostrado ser milagrosa. De otra forma, como lo señaló el asesinado sacerdote y sociólogo jesuita Segundo Montes, no podría explicarse la supervivencia, en las décadas pasadas, de muchos centenares de miles de personas con ingresos económicos inferiores al precio oficial de los alimentos que consumen.

Un viejito artrítico traslada una paila con las tortillas calentitas que acaban de hechar las hijas de Concha, la que vende hamacas y trajes típicos. Los chalatecos de la zapatería le regalan un par al recibirlas. Se arrima donde ña Rosa y ésta le completa la ración con un poco de queso. Como muestra de lealtad y transacción tácita él le cuida la venta hasta que ella se desocupa. Teresa, la muchacha del puesto de enfrente le tiene la beba en brazos mientras Francisca termina de comer, consigue algo para la cena, y le lleva el té que le sobró a Pepe, el barrendero, que se lo ponderó tanto para los riñones.

Las recientes guerras, en Nicaragua, El Salvador y Guatemala, permitieron revivenciar estas situaciones. El proceso de fondo se comprobó en ambos aspectos sugeridos:

- La interdependencia personal. El sentimiento de depender del otro, sin cuya disposición afectiva peligra "mi espalda". Investigar quién es el eslabón más débil del grupo para fortalecerlo.

- La búsqueda de protecciones comunitarias. Reunirse para hablar del enemigo común.

Se perfilaron nuevos recursos de salud mental. En la guerra de El Salvador los principales agentes de salud mental no fueron psicólogos ni psiquiatras, sino los llamados trabajadores políticos. Estas eran personas con convicción sobre lo que convenía hacer, que manejaban una información más completa de la situación y que acompañaban en su vida cotidiana a un grupo determinado. Compartían tareas, distracciones, peligros, noches de vigilancia, etc. Pero, además, contribuían en la solución de los problemas, de índole diversa (zapatos, novia, trabajo, hijos, libros, distracciones, comida, enfermedades, miedos, etc.), que afectaban a cada uno. El apoyo era integral y concreto, al igual que las demandas. La no-profesionalización de los trabajadores de salud mental preservó el valor de sus redes sociales como recursos de salud mental, y el carácter integral y cotidiano de su acompañamiento. 
En las recientes guerras populares centroamericanas se puso en evidencia, como una sentencia casi religiosa, cuáles grupos de combatientes tenían más posibilidades de sobrevivir en su lucha. Los atributos de la supervivencia estaban fundamentalmente en la calidad relacional del grupo o de sus relaciones sociales. Un grupo con mucha preparación técnica, pero desprovisto de relaciones de cooperación y solidaridad estaba condenado a desaparecer rápidamente. Si los liderazgos no habilitaban espacios de reciclaje del poder, la vida de sus grupos se fragilizaba. En esas condiciones, el fracaso relacional se continuaba rápidamente con la desaparición física que le otorgaba una elocuencia patética.

Pero la guerra, en Centroamérica, trajo también una gran disputa a nivel tecnocientífico sobre los enfoques de las intervenciones de salud mental. Fue dentro de ese marco, de contextos con demandas básicas de poblaciones en gran dificultad para sobrevivir y discusiones teóricas de especialistas con pretensiones de mayor especialización, que la salud mental de base aparece; primero, como un término más de la jerga propia de los planificadores sociosanitarios internacionales para señalar una simple extensión de la cobertura. Sin embargo, el compromiso humano con la lucha por las necesidades ineludibles de la gente alimentó los términos con un contenido tan real y genuino, que desbordó completamente la estrecha semántica inicial nacida, a su vez, de una intencionalidad igualmente estrecha.

En los campos de refugiados de Centroamérica, los ciclos de aprendizaje de la impotencia se habían cumplido tan bien, que la oferta de cualquier cosa, incluida la atención psicológica, generaba demandas masivas. Si se hubieran regalado sesiones de electroshock, probablemente hubieran habido inmensas colas para recibirlos.

Identificamos los procesos de desujetivación o aprendizaje de la impotencia como el trasfondo o dimensión subjetiva de la exclusión humana. Es decir, la resultante de la secuencia de "infinitas" derrotas cotidianas que el sistema social impone al YO. Y que, circularmente, van condicionando su claudicación anticipada ante los desafíos de la vida. Esto sería la antítesis de la salud mental de base.

No vemos la salud mental como "un estado de paz" o éxtasis estático; que en definitiva podría ser el de la droga o el de un delirante en trance. La identificamos en el entusiasmo por ser sujeto de cambio de realidades privadoras de poder socio-relacional.

Recordamos que Minuchin descubrió, ya en la década de los sesenta, como en las familias de los barrios marginales de Filadelfia (Estados Unidos) se empobrecía drásticamente la comunicación, la expresión afectiva y la producción subjetiva en general.

Los aportes teóricos del psicólogo y sacerdote jesuita Ignacio Marín-Baró —asesinado en noviembre de 1989 por el principal batallón elite antisubersivo 
(adiestrado íntegramente en Estados Unidos), en las instalaciones de la Universidad Católica Centroamericana-, habían abonado el terreno en tomo a la importancia de los grupos organizados ("grupos con historia") en la vida de la comunidad; de la calidad de las relaciones sociales y los "traumas psicosociales colectivos", como indicadores de la afectación (de base) y de la codificación de la vida cotidiana en la estructuración de las relaciones sociales.

Pero el mandato institucional de psicopatologizar las dificultades integrales de las personas y los grupos encontró suficiente eco en el condicionamiento de la cooperación internacional por privilegiar modelos que generen dependencia tecnológica progresiva, que contribuya a enmascarar la responsabilidad del sistema por medio de complejizaciones y tecnicismos artificiosos, y la culpabilización de las personas. Las cuales, entonces, se pierden en "su" árbol fantasmal y dejan de ver el bosque real. (La AID ofreció muchos millones de dólares para que la atención de la población desposeída se concentrara en el tratamiento médico del PTSD, descontextualizando las afectaciones y deshistorizando las identidades.) Tampoco existió, en un inicio, suficiente desarrollo conceptual propio para sistematizar la experiencia de la guerra, superar el desvío de la atención hacia la defectuosidad de la gente y concentrarse en los procesos de satisfacción de las necesidades humanas básicas, a través de una práctica cotidiana de empoderamiento y movilización afectiva, apoyada por la identidad construida.

En el plano operativo, Luciano Carrino fue quien señaló y probó, como punto de partida, los cuatro elementos centrales de la salud mental de base: $(a)$ el apuntar hacia la afectación común de una población; (b) el carácter de actuar como estímulo, en un sentido estratégico; (c) la identificación de los ciclos afectivos negativos, y (d) La activación de dinámicas comunitarias que desencadenan círculos de afectividad constructiva.

Después llamamos afectación de base (o efecto de base) al cuadro clínico o subclínico difuso e inespecífico, caracterizado en forma variable por manifestaciones en diversas esferas: anatómica, funcional, afectivo-emocional, cognitiva y psicosocial.

La privación del ejercicio de poder socio-relacional, que tal vez alguna persona sufrirá y procesará "por su cuenta", lejos de toda dinámica comunitaria. Pero lo cual no le cambia su esencia de situación que provoca un proceso o afectación circular de base. Individual o colectivamente, las personas suelen compartir (cada día más) una configuración o estructura relacional que las priva de ejercer su poder socio-relacional. Con frecuencia progresiva esta situación se institucionaliza, es decir, depende del accionar de las instituciones del sistema social. Ella conduce, en primera instancia, a afectaciones psíquicas variadas, difusas e inespecíficas que pueden, en segunda instancia, hacerse específicas en un cuadro clínico de clasificación nosológica reconocible, como episodios depresivos, trastornos somatomorfos, disfunciones sexuales, trastomos de compor- 
tamientos disociales, trastornos de ansiedad, trastomos disociativos, trastornos fóbicos, trastornos obsesivo-compulsivos. La manifestación más inespecífica y general es cierta infelicidad o insatisfacción existencial. Posteriormente se altera la rutina de vida: sueño, alimentación, actividades de concentración, de gratificación (abuso alcohólico y demás adicciones). Según investigaciones de psiquiatría y salud pública, aproximadamente la mitad de la población del mundo occidental se encuentra en esas condiciones.

A la situación donde se inicia y desarrolla el proceso de privación del ejercicio de poder socio-relacional la llamamos situación primaria o de base.

Antes de seguir adelante, se hace necesario definir qué entendemos por "la situación" desde la perspectiva de la salud mental de base. Al decir "situación" queremos significar no simplemente el cuadro material que rodea a la persona. Con ese término incluimos al sistema de relaciones sociales que la ubican en roles determinados, posiciones de poder, y de capacidad transaccional y afectiva.

En los individuos se expresan los síntomas. En la situación es donde se configuran más claramente los recursos de los que podemos echar mano para dinamizar los procesos terapéuticos.

El trabajo con los procesos comunitarios, donde el foco está "entre" las personas y no dentro de ellas, permite activar otros recursos terapéuticos (frecuentemente integrados a la vida cotidiana y a la mitología "natural") y moverse en el nuevo mapa de las circularidades psicosociales. Hecho de suma importancia para nuestra estrategia "ecológica" de activar los procesos terapéuticos naturales de la comunidad, que vienen funcionando con éxito desde hace miles de años. Por otro lado, la comunión del sufrimiento psíquico (del mismo tipo) funde el concepto de medio colectivo con el de compartir vivencias.

Un habitante de San Fernando, de Chalatenango, no necesita conocer personalmente a otro habitante, supongamos, de San Fernando, de Morazán, para compartir con él un mundo subjetivo, incluyendo especialmente las vivencias de sufrimiento psíquico.

En síntesis, los procesos de afectación psíquica de base pueden diagnosticarse y tratarse tanto a través de la investigación de casos individuales, a condición de que se los contextualice, como a través de una práctica comunitaria. Además, siempre debería intentarse combinar ambos tipos de intervenciones. 
Los campos de refugiados dieron ocasión para poner en práctica estos principios de la salud mental de base. La ayuda exterior con Carrino comenzó, por primera vez, a decidirse respetando la decisión, identidad y organización locales, así como sus prioridades. Luego, se analizaba conjuntamente, estimulando el rol de sujetos de los participantes, hasta decidir qué dinámicas comunitarias activaría cada recurso exterior. Una dinámica básica la constituyó la circularidad afectiva de los grupos en dificultad, en la cual la ayuda exterior a un grupo se extendía a otro para que éste retroalimentara al primero con un nuevo aporte.

La satisfacción de las necesidades humanas básicas se vio como un recurso esencial para la salud mental. Pero también se fue clarificando que el proceso dependía no sólo de que realmente se atendieran esas necesidades prioritarias, sin lo cual las técnicas de relajación y las sesiones de "terapia" se transformaban en un pasatiempo ("vacilar" a la gente), sino del rol que les tocaba jugar a los afectados en esa satisfacción de necesidades. Específicamente del grado con que asumían una posición de sujetos.

Posteriormente, buscando soporte teórico en el trabajo sistémico con redes sociales, vimos cómo al concepto de los ciclos afectivos negativos se superponía el de aprendizaje de la impotencia (en las comunidades con carencias fundamentales crónicas). Esto completó la configuración del estímulo como cada una de las pequeñas victorias cotidianas, que inician un ciclo de aprendizaje del ejercicio de poder socio-relacional. Ellas producen, en primer lugar, cierto placer indispensable para encontrarle sentido al esfuerzo de vivir y provocar mantener la aptitud del sustrato biológico; luego se descubren nuevos paradigmas para encauzar la búsqueda de respuestas a las demandas de la realidad. Y, por último, se enriquece la capacidad transaccional de la persona y se incrementan sus alternativas de relaciones sociales y de socializar dificultades. La calidad del estímulo de salud mental de base depende principalmente del grado con que cada individuo activa el ejercicio de poder socio-relacional.

Se consolidó la estrategia de atender la situación, más esencialmente que al individuo, y el ser humano con historia antes que los síntomas.

Antes de los trabajos de Carrino, la salud mental de base se consideraba como la simple extensión de una cobertura de salud mental para el primer nivel de complejidad de servicios. Como enfoque sanitario, esto planteaba simplemente aumentar el número de psicólogos hasta que pudieran dar consulta, a nivel de consejería y técnicas de contención psicológica, en cada comunidad. Durante la efervescencia de la posguerra por trabajar en las comunidades afectadas, pasó a ser concebida como la organización de actividades colectivas en los espacios públicos, principalmente de diversión.

Ahora pensamos que no basta con llegar a "dar consulta" a la comunidad. Para la salud mental de base, el sitio, geográficamente hablando, es secundario; 
puede desarrollarse tanto en el trabajo con la comunidad como en la atención de casos particulares, todo depende del enfoque con que se prioricen los recursos por utilizar. Si utilizamos prioritariamente el estímulo de las pequeñas victorias cotidianas para codificar el aprendizaje del ejercicio de poder socio-relacional; si apuntamos hacia las afectaciones comunes de una población; si activamos dinámicas comunitarias $y / o$ intragrupales movilizadoras de la afectividad, entonces estamos haciendo salud mental de base, no importa en qué lugar. Tal vez la forma más sintética de expresarlo sería decir que hacer salud mental de base es dinamizar la afectividad presente en las comunidades.

La superación del modelo biomédico no garantizó el trabajo de salud mental de base, porque del esquematismo de querer establecer qué son medidas terapéuticas, cuáles preventivas, etc., se pasó a hablar como que todo lo que gusta es salud mental de base. Así, el deporte, la recreación, las actividades artísticas y finalmente... ¡ todo! sería salud mental de base. Eso ocurrió porque muchas prácticas, especialmente las de los psicólogos sin visión de salud pública, se quedaron en lo superficial de las actividades. El deporte no se convierte en un recurso de salud mental de base por sí mismo, sino en la medida que signifique un estímulo cotidiano para ejercitar el poder socio-relacional. Evidentemente, si se institucionaliza una obligación de jugar futbol, y hacerlo de determinada forma, sin sentido para la identidad y los proyectos de vida personales, se mejorarían los músculos pero no la salud mental de base.

La activación de determinadas dinámicas comunitarias que movilizan la afectividad se percibe en su verdadera dimensión, cuando reconocemos a la comunidad como un organismo vivo. Para nosotros, los órganos de ese cuerpo viviente pueden identificarse en los escenarios o ámbitos psicosociales que describió Rotelli: hogar, trabajo y bazar; conjunto que nosotros completamos de esta forma: hogar, trabajo, transaccional cotidiano, lúdico-experimental y trascendental.

A nivel técnico hablamos de Sistemas co-integradores de la subjetividad personal para precisar al máximo este valiosísima y estratégica conceptualización triestina. En ella los espacios son reales, pero no están circunscriptos al plano material (el esfuerzo físico del trabajo, las paredes del taller, la cancha de fútbol, etc.), sino que incluyen fundamentalmente la dimensión simbólica y afectivo-emocional. El ámbito hogar, como lo explicó Rotelli, va más allá de las relaciones intrafamiliares. Incluye los microambientes personales, más o menos íntimos, que configuran las "capas exteriores" de nuestra identidad y la interfaz de reflexión con el mundo de los demás. A veces, parte del hogar puede ser un banco de plaza o una roca lejana. Cuando ese entomo se personaliza, ya sea objetivamente (con adornos, objetos típicos, fetiches, imágenes emblemáticas o estéticas) o simbólicamente (dando nombres a la roca, al árbol, al bosque o al cerro), la identidad se fortalece en forma estable. 
Procuramos primero investigar su existencia, sus limitaciones o su ausencia en cada situación. Luego verificamos la calidad relacional dentro de cada uno. Finalmente, reconstruimos el flujograma afectivo y de poder dentro de cada uno.

Las experiencias de salud mental de base en Centroamérica no se dieron como consecuencia de una demanda por "liberar" enfermos de la institucionalidad psiquiátrica, bastante débil y aislada comparativamente, sino por la necesidad de fortalecer a la gente en su lucha cotidiana por sobrevivir (a un estado de carencia y riesgo social del cual las guerras han sido sólo agudizaciones). Se trataba de despertar los sentimientos de vida y de visibilizar un enemigo que fuera más que la muerte. Siendo el enemigo común el mayor aglutinante social.

Con su "centro de gravedad" en la vida comunitaria misma, la salud mental de base encontró en el fenómeno de la guerra una circunstancia que le permitió contrastar, con mayor claridad, los efectos del movimiento de las estructuras afectivas, de las relaciones y del poder.

Pero las condiciones de esa afectación compartida iban preñadas por un sentimiento de avance histórico: de que se estaba caminando, segundo a segundo, hacia algo con mucho sentido. De esta forma, el concepto de enfermo se relativizaba porque, si se va hacia algo definitivo, lo importante pasa a ser no perder la marcha, sino avanzar más; y·no como se está en un momento vivido como transitorio. De la misma manera que un ciclista se libra de ser enfermo si su dolor y angustia son experimentados en una situación de carrera hacia la meta. A la inversa, si me detengo, sin moverme psicohistóricamente, el mínimo dolor se volverá intolerable, porque toda mi autoorganización psíquica estará en función del cómo estoy. Sacar de la inmovilidad psicohistórica fue el principal y masivo recurso terapéutico durante la guerra de El Salvador. Por eso, muchos guerrilleros hambrientos, sucios y amenazados, cuando se les preguntaba cómo se sentían respondían: "Jodidos pero contentos".

El otro gran elemento síntesis de la salud mental de base fue, como dijimos, el concepto de estimulación de la subjetividad de las personas. En este sentido, luego de hacer la primera sistematización importante del trabajo de salud mental de base en Centroamérica (1995), tratamos de desarrollar cierta teoría de la estimulación para la salud mental de base. Entonces, fue que definimos para ella: direccionalidad, calidad y sintaxis.

El estímulo de salud mental de base debe dirigirse hacia el aprendizaje del poder socio-relacional. Articularmente identificamos esas experiencias cotidianas vividas como pequeños pero significativos triunfos de la identidad propia. El conjunto de estas victorias con identidad arman el proceso circular de aprendizaje del poder socio-relacional; en oposición al círculo de aprendizaje de la impotencia, que propicia el sistema macrosocial vigente. 
La calidad del estímulo alude a qué proporción de esfuerzo personal y colectivo se traduce en ejercicio de roles de sujeto para las personas afectadas en su salud mental de base.

La sintaxis se refiere al setting del estímulo en el complejo comunicacional que se desarrolla con la comunidad. Ponemos el ejemplo con una caricatura de Quino, donde se muestra a un náufrago que clama: “Señor, qué aburrimiento!”. Acto seguido aparece un ángel con una sorprendente valijita, pero la cara del náufrago trasluce desilusión y hasta rabia cuando lo que hace el ángel es ponerse a jugar a las cartas con él. Las imágenes enseñan mucho acerca de cómo un estímulo real, bajo una sintaxis determinada, puede dejar de serlo y hasta convertirse en un bloqueador. Es decir, jugar a las cartas distrae y divierte, pero presentado como la opción principal, se convierte en un desestimulante mensaje traducible en: "No intentes nada para cambiar tu situación, sólo te queda evadir la realidad jugando a las cartas". La sintaxis cambiaría si el ángel introdujera primero el estímulo de hablar sobre balsas, señales, botellas con mensajes, planes para cambiar la situación, etc., y recién después propusiera el juego de cartas, que ahora se traduciría como: "Diviértete para estar mejor para enfrentar las tareas que pueden permitir el cambio de tu situación afectante".

Juntando la estimulación estratégica con la movilización afectiva convergemos a una práctica reconocible en el campo de la rehabilitación psicosocial:

- El acompañamiento de la vida cotidiana

- El acompañamiento en la proyectación de vida con identidad propia.

Estos acompañamientos los referimos a un carácter humano, sin tecnicismos. La idea es que la especificidad la ponga la historia y la personalidad del afectado. Para ello debemos retirar los esquematismos nosologizantes y permitir que aquéllas cobren un relieve institucionalmente libre. 